Judged by the number of paroxysms of cough, about $30 \%$ of attacks in childiren under 1 year of age were severe, but, as would be expected, this proportion was less in older children. Among children aged 1 to 4 years there was a slight tendency for attacks to be less severe in vaccinated than in unvaccinated children. The results, however, confirm that pertussis is still a troublesome illness, especially in infancy, and effective prevention remains desirable.

The survey is of course concerned with vaccines previously in use and provides no evidence about the efficacy of those currently available.

The findings, however, clearly indicate that the efficacy of much of the pertussis vaccine in use for some years before 1968 required improvement; and also that in future the efficacy of pertussis vaccines should be kept under constant surveillance in the field.

The report was prepared by Dr. J. D. Abbott, Dr. E. H. Gillespie, Dr. Sheila Polakoff, and Dr. T. M. Pollock.

We are grateful for the detailed information about pertussis vaccines supplied by Glaxo Laboratories Limited and the Wellcome Research Laboratories and for the co-operation and support of members of these firms during the study.

We thank Mr. G. H. Turner for the preparation of the monospecific typing sera and the Wellcome Research Laboratories for the gift of the sera; Dr. F. Sheffield (Medical Research Council Laboratories, Hampstead), and Dr. Jean M. Dolby (Lister Institute) for much help with the serotyping.

We are grateful for the interest shown in this investigation by Dr. M. Sterne, Dr. J. Cameron, Dr. A. H. Griffith (Wellcome Research Laboratories), Dr. A. J. Beale, Dr. P. W. Muggleton (Glaxo Laboratories Ltd.), Dr. L. B. Holt (Medical Research Council Laboratories, Hampstead), and Professor D. G. Evans (London School of Hygiene and Tropical Medicine).

We are greatly indebted to the general practitioners who notified suspected cases of whooping-cough, and to the many members of the Health Departments, especially the Health Visitors who collected specimens and made repeated home visits, as did the general practitioners in Scotland.

\section{REFERENCES}

Cruickshank, R. (editor) (1965). Medical Microbiology, 11th ed., p. 766. Livingstone, Edinburgh.

Lacey, B. W. (1957). The Association of Clinical Pathologists. Broadsheet, No. 17.

Medical Research Council (1951). British Medical fournal, 1, 1463.

Medical Research Council (1956). British Medical fourmal, 2, 454.

Medical Research Council (1959). British Medical fournal, 1, 994.

Preston, N. W. (1963). British Medical fournal, 2, 724.

Preston, N. W. (1965). British Medical fournal, 2, 11.

Stuart, R. D. (1959). Public Health Reports, 74, 431.

Wilson, A. T., Henderson, I. R., Moore, E. J. H., and Heywood, S. N. (1965). British Medical fournal, 2, 623.

\title{
Action of Dopamine on the Human Iris
}

\author{
A. S. D. SPIERS, * M.B., PH.D., M.R.A.C.P. ; D. B. CALNE, $†$ D.M., M.R.C.P.
}

ummary : Dopamine eye drops produce marked dilata-
tion of the pupil in man. This mydriatic effect is
inhibited by pretreatment with guanethidine. It is there-
fore concluded that dopamine acts indirectly via
adrenergic nerve endings, rather than exerting a direct
effect on adrenergic receptors in the dilator pupillae
muscle. In this respect dopamine resembles the phenyl-
alkylamines, such as tyramine, rather than the catechol-
amines, adrenaline and noradrenaline.

If dopamine acts by releasing noradrenaline from adrenergic nerve endings, high concentrations of dopamine could lead to depletion of noradrenaline stores, since synthesis might be unable to keep pace with release. This could be the explanation for the orthostatic hypotension found in patients taking L-dopa for Parkinsonism.

\section{Introduction}

In Parkinsonism there is marked depletion of dopamine in the corpus striatum (Hornykiewicz, 1966) and it appears probable that the syndrome results from selective impairment of dopaminergic neurones. Recent attempts to enhance the level of brain dopamine by prolonged administration of L-dopa have resulted in substantial clinical improvement (Cotzias et al., 1968, 1969 ; Duvoisin et al., 1968 ; Calne et al., 1969b). However, in many of the patients treated in this way hypotension has been a troublesome though usually transient side-effect.

* Nuffield Dominion Travelling Fellow.

+ Wellcome Fellow in Clinical Pharmacology.

Medical and Neurological Units, University College Hospital Medical School, London W.C.1.
Studies of urinary phenolic amino acid metabolites in patients treated with L-dopa indicate a considerable increase in dopamine levels with only small increments in noradrenaline (Calne et al., 1969a). Two explanations for the hypotension have been put forward-either that dopamine, formed from administered L-dopa, acts directly on specific vasodilator receptors (Eble, 1904), or that dopamine plays the part of a partial agonist, blocking $\alpha$-adrenergic receptors on the blood vessels. It is unlikely that the vasodilator $\beta$-adrenergic receptors are implicated, since in animal experiments the hypotensive effects of dopamine are not influenced by $\beta$-receptor blockade (McDonald and Goldberg, 1963).

The $\alpha$-adrenergic receptors of the dilator pupillae muscle are homologous to the $\alpha$-adrenergic receptors on the blood vessels (Turner and Sneddon, 1968), so ocular instillation of drugs has been studied in the human eye in an attempt to elucidate further the pharmacology of dopamine in man, and possibly explain its hypotensive effects. The eye has several advantages for this type of study. Direct observations of pupillary size are simple and rapid, and since total doses of drugs are small the hazards of untoward effects, particularly on the cardiovascular system, sre reduced.

\section{Materials and Methods}

Eye drops of dopamine hydrochloride were made up in $10 \%$ solution buffered with sodium bicarbonate and sodium sulphite to $\mathrm{pH} 6.5$ and sterilized by passage through a Millipore filter. In every case eye drops were prepared immediately before use. Guanethidine was given as a $5 \%$ solution in a proprietary ophthalmic vehicle (Ismelin eye drops). Drops were instilled into one eye during each study and the other eye was used as 
a control. Pupil diameters were measured by a "blind" observer, using the pupillometer of a standard ophthalmoscope.

Studies were made in volunteers who were either members of the research staff or patients in the medical wards, excluding those with ocular abnormalities other than simple refractive errors. Seventeen series of observations were made on 16 subjects-11 men and 5 women-aged 19-73 years. They were divided into two groups, A and B. Group A received either two or three dopamine eye drops once every hour until a substantial change in pupillary diameter was observed. Subjects in Group B were pretreated with two guanethidine eye drops at 12-hourly intervals for varying periods before administration of dopamine (two for 60 hours, one for 36 hours, three for 14 hours). One volunteer received a single dose of five guanethidine eye drops 15 minutes before dopamine was begun. Group B subjects received dopamine eye drops at hourly intervals as for Group A. Three subjects in Group A also received drops of buffer solution without dopamine, every hour into the control eye.

In view of the differing pharmacological responses that have been reported for pigmented and unpigmented irides (Obianwu and Rand, 1965 ; Sneddon and Turner, 1969), the colour of each subject's eye was recorded and they were allocated at random into either Group A or Group B. There were 6 blueand 4 brown-eyed subjects in Group $A$, and 5 blue- and 2 brown-eyed subjects in Group B, one volunteer being investigated twice and appearing in both groups. The unusual proportion of blue-eyed subjects among the volunteers as a whole was due to deliberate selection, since blue irides are more susceptible to the action of various drugs and might be expected to provide a more sensitive test system. All the subjects were Caucasian.

\section{Results}

Group A.-Administration of dopamine alone consistently resulted in dilatation of the pupil. Mydriasis usually began within two hours of the first instillation, and reached its maximum at about $4 \frac{1}{2}$ hours (see Table). The most rapid responses, obvious dilatation in half an hour, were seen in two subjects with blue eyes. Occasionally the response was slower, taking up to six hours to appear. In the initial stages of enlargement the pupils commonly became elliptical (Fig. 1) or eccentric, but as dilatation advanced these irregularities usually disappeared (Fig. 2). The maximum dilatations observed in different subjects varied from 1 to $6.5 \mathrm{~mm}$. From the Table it can be seen that the mean values for rapidity and magnitude of response of the iris to dopamine differ little-when eyes of each colour are compared with the group as a whole. When dopamine eye drops were discontinued a decrease in mydriasis occurred within two hours, and the pupil returned to normal in three to four hours. However, in three cases, after initial marked dilatation, the pupil grew smaller while dopamine administration was continued. Two of these cases were treated with eye drops of $10 \%$ phenylephrine, a direct-acting $\alpha$-adrenergic agent, and in both the pupil size increased once more. Pupils dilated by dopamine often constricted in response to accommodation. A typical response to the administration of dopamine alone is shown in Fig. 3. No pupillary changes were observed in the three eyes treated with buffer solution alone.

Response of the Iris to Dopamine in Group A Patients

\begin{tabular}{|c|c|c|c|}
\hline & $\begin{array}{c}\text { Blue Eycs } \\
(6)\end{array}$ & $\underset{(4)}{\text { Brown Eyes }}$ & All Subjects \\
\hline $\begin{array}{l}\text { Mean time to onset of dilatation (hours) } \\
\text { Mean time to maximum dilatation } \\
\text { (hours) } \\
\begin{array}{cccc}\text { Mean maximum dilatation } & \text { observed } \\
\text { (mm.) } & . . & . . & . .\end{array}\end{array}$ & $\begin{array}{r}2 \cdot 37 \\
-4 \cdot 21 \\
2 \cdot 9\end{array}$ & $\begin{array}{l}1.56 \\
5 \cdot 19 \\
3.5\end{array}$ & $\begin{array}{l}2 \cdot 05 \\
4 \cdot 6 \\
3 \cdot 15\end{array}$ \\
\hline
\end{tabular}

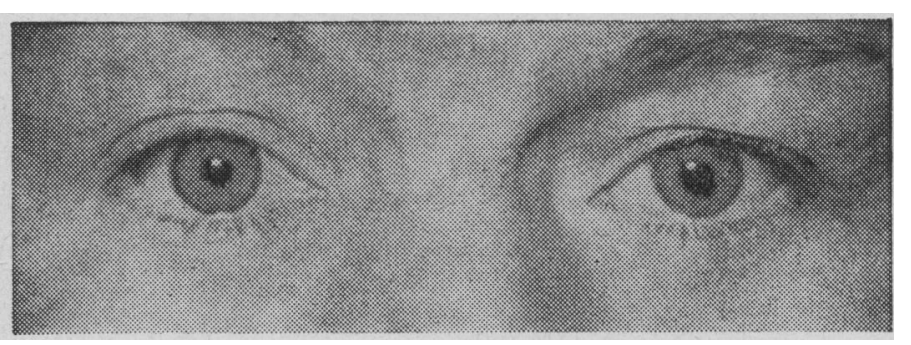

FIG. 1.-Early stage of response to dopamine. The left pupil is becoming elliptical.

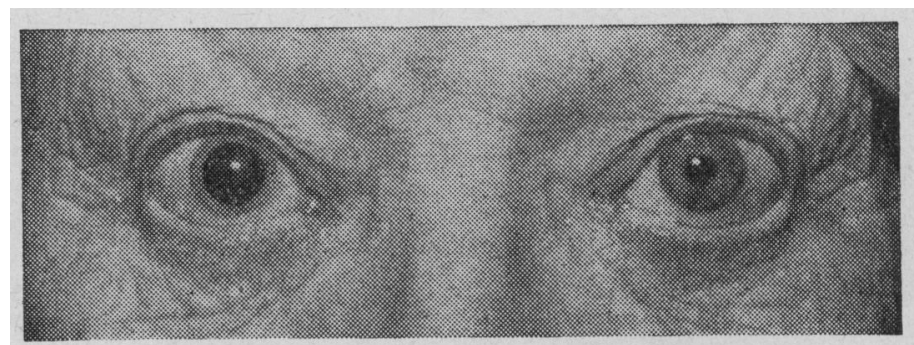

FIG. 2.-Maximal response to dopamine. Mydriasis is extreme.

Group B.-In four of the six subjects pretreated with guanethidine for 12 hours or more the response to dopamine was either abolished or substantially reduced. The patient pretreated for only 15 minutes developed the usual mydriasis. Fig. 4 shows the pupillary responses of one subject who showed marked mydriasis following administration of dopamine alone in the right eye and underwent observation one week later, with dopamine instilled into the same eye after pretreatment with guanethidine. Although administration of dopamine was continued longer than on the previous occasion, the response
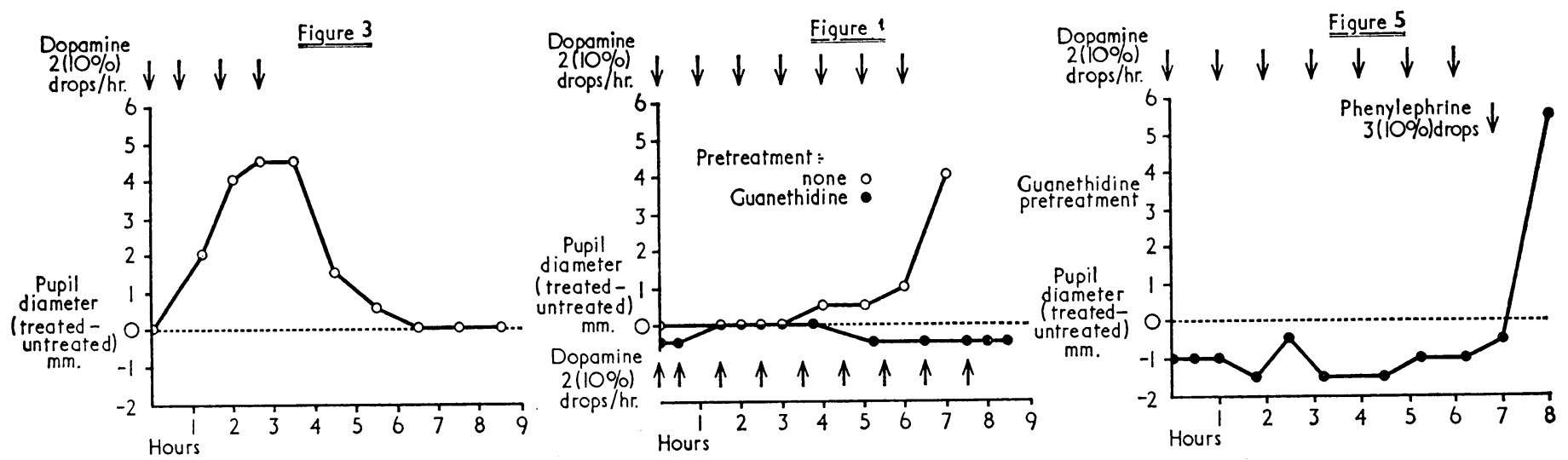

Fig. 3.-Typical pupillary response to instillation of $10 \%$ dopamine eye drops. Fig. 4.- Responses of the same eye to dopamine on two occasions a week apart. On the second occasion, after pretreatment with guanethidine eye drops, there is no mydriasis with dopamine. Note: Since pretreatment with guanethidine causes a mild to moderate miosis, the value of (diameter treated pupil)-(diameter untreated pupil) is negative at the beginning of dopamine administration in Figs. 4 and 5 . Fig. 5. - Subject pretreated with guanethidine eye drops. Although no mydriasis the beginning of dopamine administration in for six hours, instillation of $10 \%$ phenylephrine produces marked pupillary dilatation. 
was completely abolished. In another subject (Fig. 5), the eye showed a complete lack of response to dopamine after guanethidine, although responding briskly to the instillation of $10 \%$ phenylephrine.

In the four patients in whom the response to guanethidine was considered adequate (see Discussion) the mean maximal dilatation of the treated pupil was $0.37 \mathrm{~mm}$. This differs significantly $(P<0.05)$ from the corresponding figure for those patients receiving dopamine alone $(3.15 \mathrm{~mm}$.).

No significant adverse effects were experienced by any of the subjects in Groups A or B. Mild transient impairment of accommodation occurred in only one subject, in whom mydriasis was extreme.

\section{Discussion}

These results show dopamine to be a slow-acting but potent and consistent mydriatic agent. Since dopamine mydriasis is seldom accompanied by impairment of accommodation, it is unlikely to be due to cholinergic blockade. Evidently the ocular instillation of dopamine leads to stimulation of the $\alpha$-adrenergic receptors of the dilator pupillae muscle. There are several mechanisms by which such stimulation might occur: (1) direct action of dopamine on the $\alpha$-receptors; (2) conversion of dopamine by $\beta$-hydroxylation to noradrenaline, which then excites the $\alpha$-receptors; (3) release of noradrenaline from adrenergic nerve endings by dopamine ; (4) blockage by dopamine of the normal re-uptake of noradrenaline into adrenergic nerve endings ; (5) blockage of monoamine oxidase and catechol $o$-methyl transferase activity by dopamine. The present findings suggest that (1) is unimportant, while (3) may be the principal mode of action of dopamine.

In the majority of subjects guanethidine blocked the action of dopamine. One subject who reacted to dopamine after guanethidine almost certainly did so because the duration of pretreatment was intentionally very brief (15 minutes). However, two subjects who had received guanethidine for a longer period (14 and 60 hours respectively) developed definite mydriasis when treated with dopamine. It seems probable that in these subjects pretreatment was still inadequate. Even when $10 \%$ guanethidine eye drops are used maximal effect as measured by production of ptosis takes seven days to develop (Sneddon and Turner, 1966a). Furthermore, in some patients guanethidine may penetrate only poorly to the iris, since miosis occasionally does not develop even after the drug has been instilled into the conjunctiva for several weeks (Crombie and Lawson, 1967). Long-term pretreatment was not possible in our volunteer subjects.

The action of guanethidine on adrenergic nerve endings is complex. Initially it liberates noradrenaline, giving a transient sympathomimetic reaction. Subsequently it prevents the release of noradrenaline by nerve impulses, leading to prolonged sympathetic blockade. Continued administration depletes the noradrenaline stores in the nerve endings, and in addition guanethidine interferes with the process of active re-uptake of noradrenaline by nerve endings (Iversen, 1967). All these effects of guanethidine are mediated at the postganglionic adrenergic nerve ending. As guanethidine blocks the action of dopamine it is probable that dopamine acts at this site also. The only known effect of guanethidine on adrenergic receptors is potentiation of their response to applied catecholamines, possibly as a result of denervation supersensitivity (Sneddon and Turner, 1967), which is clearly not occurring with dopamine. Thus, while guanethidine eye drops will potentiate the mydriatic effects of phenylephrine, which acts directly on $\alpha$-adrenergic receptors (Sneddon and Turner, 1967), depletion of noradrenaline stores by guanethidine abolishes the pupillary response to tyramine, which acts indirectly by releasing noradrenaline from adrenergic nerve endings (Sneddon and Turner, $1966 \mathrm{~b}, 1967)$. Our results suggest that the action of dopamine resembles that of tyramine and similar drugs such as ephedrine and amphetamine, and is dissimilar from the actions of phenyl- ephrine and noradrenaline. A similar conclusion was drawn from investigations of noradrenaline levels in guinea-pig heart following parenteral administration of high doses of dopamine (Harrison et al., 1963). The unusual pharmacological status of dopamine as both a precursor and a releasing agent for noradrenaline is of considerable interest.

Further support for the hypothesis that the mydriatic action of dopamine is due to the release of noradrenaline from adrenergic nerve endings is provided by the finding (Eränko and Räisänen, 1966) that exposure of the rat iris to dopamine in vitro results in the displacement of most of the noradrenaline from the sympathetic nerve network in the dilator pupillae muscle. It is possible that the decrease in mydriasis observed in three subjects in the present study while the administration of dopamine was continued was the result of exhaustion of the noradrenaline stores of the sympathetic nerve endings. The retention, under these conditions, of a normal response to the direct-acting phenylephrine makes it unlikely that the diminution of mydriasis was due to functional impairment of the $\alpha$-receptors themselves or fatigue of the dilator muscle fibres.

Treatment of Parkinsonism with L-dopa results in increased dopamine production (Calne et al., 1969a). The orthostatic hypotension frequently observed in these patients might be explained by depletion of the noradrenaline stores due to the action of high concentrations of dopamine at sympathetic nerve endings, if the synthesis of noradrenaline is unable to keep pace with its release. That release may outstrip synthesis has been demonstrated in animal experiments, where high parenteral doses of dopamine produced depletion of noradrenaline stores in the heart (Harrison et al., 1963). However, in patients treated with L-dopa there are other possible mechanisms, several of which may be interacting. High concentrations of dopa itself can cause release of noradrenaline from sympathetic nerves (Eränko and Räisänen, 1966), and a direct peripheral action of administered L-dopa to produce hypotension has not been excluded. As L-dopa enters the central nervous system readily it is also possible that an action on the vasomotor centre may be important. Investigation of these possibilities is proceeding.

We are grateful to Professor D. R. Laurence and Dr. R. A Webster for much helpful advice and discussion. We are indebted to $\mathrm{Mr}$. T. M. French for the formulation of dopamine eye-drops. The illustrations were prepared by Mr. V. K. Asta and by the photographic department of University College Hospital Medical School.

\section{REFERENCES}

Calne, D. B., Karoum, F., Ruthren, C. R. J., and Sandler, M. (1969a). British fournal of Pharmacology. In press.

Calne, D. B., Stern, G. M., Laurence, D. R., Sharkey, J., and Armitage, P. (1969b). Lancet, 1, 744 .

Cotzias, G. C., Papavasiliou, P. S., Aronson, R. B., and Mena, I. (1968). Third Symposium on Parkinson's Disease. Edinburgh. In press.

Cotzias, G. C., Papavasiliou, P. S., and Gellene, R. (1969). New England fournal of Medicine, 280,337 .

Crombie, A. L., and Lawson, A. A. H. (1967). British Medical fournal, 4,592 .

Duvoisin, R., Barrett, R., Schear, M., Hoehn, M. M., and Yahr, M. (1968). Third Symposium on Parkinson's Disease.' Edinburgh. In press.

Eble, J. N. (1964). Fournal of Pharmacology and Experimental Therapeutics, 145, 64 .

Eränko, O., and Räisänen, L. (1966). In Mechanisms of Release of Biogenic Amines, edited by U. S. Von Euler, S. Rosell, and B. Urnäs, p. 73. Oxford, Pergamon.

Harrison, W. H., Levitt, M., and Udenfriend, S. (1963). Fournal of Pharmacology and Experimental Therapeutics, 142, 157.

Hornykiewicz, O. (1966). Pharmacological Reviews, 18, 925. Iversen, L. L. (1967). The Uptake and Storage of Noradrenaline Sympathetic Nerves. Cambridge, Cambridge University Press.

McDonald, R. H., and Goldberg, L. I. (1963). Yournal of Pharmacology and Experimental Therapeutics, 140,60 .

Obianwu, H. O., and Rand, M. J. (1965). British Fournal of Ophthalmology, 49, 264 .

Sneddon, J. M., and Turner, P. (1966a). Lancet, 2, 525.

Sneddon, J. M., and Turner, P. (1966). Fournal of Physiology, 189, $20 \mathrm{P}$.

Sneddon, J. M., and Turner, P. (1967). Journal of Physiology, 192, 23P Sneddon, J. M., and Turner, P. (1969). Clinical Pharmacology and Therapeutics, 10, 64 .

Turner, P., and Sneddon, J. M. (1968). Clinical Pharmacology and Therapeutics, 9, 45 . 